\title{
Developing paediatric endoscopic surgery skills for trainees in the era of COVID-19: narrative review from trainee perspective
}

\author{
Christine Lam ${ }^{1}$. Carmen Sofia Chacon ${ }^{1}$
}

Received: 23 March 2021 / Accepted: 10 April 2021 / Published online: 10 May 2021

(c) The Author(s), under exclusive licence to Springer Nature Singapore Pte Ltd 2021

\begin{abstract}
Since the outbreak of Coronavirus 2019 (COVID-19) pandemic, paediatric endoscopic surgery training has taken a backseat. Simulation and virtual learning have become cornerstones in educating trainees across different surgical specialties. Paediatric minimal access surgery is an exceptionally challenging field due to the extreme variations in the size of the patients, ranging from newborns to adolescents. Finding possible solutions to continue training in this field during the pandemic will require focused efforts from the educators and leaders of paediatric endoscopic societies and universities.
\end{abstract}

Keywords Paediatric Surgery · Endoscopic Surgery Training · Laparoscopy · Thoracoscopy · Surgical Training · Simulation · COVID-19

Just over a year has passed since the worldwide outbreak of the coronavirus disease 2019 (COVID-19) pandemic. Every nation had to adapt their daily activities and witness their healthcare service stretched and modified to accommodate the rapid influx of COVID-19 affected patients. During the early outbreak in Spring 2020, there was a cessation of elective operating and redeployment of surgical trainees to intensive care units and emergency departments across the world. The Royal College of Surgeons recognised early on the impact this would have on training [1]. No literature has yet been published regarding the impact of paediatric endoscopic surgery training in response to COVID-19.

An important question is whether this issue in endoscopic training was addressed and if yes, what were the steps taken to maintain paediatric endoscopic training despite these limitations? In order to answer these questions, the effect of COVID-19 on training must be addressed. Elective lists around the world were cancelled. The operating lists that were still running, often resulted in a "dual-consultant operating" or "consultant-only" operating policy in view of completing procedures quickly, thereby minimising operating

Christine Lam

Christine.lam2@nhs.net

1 Department of Paediatric Surgery, Chelsea Children's Hospital, Chelsea and Westminster Hospital NHS Foundation Trust, 369 Fulham Road, London SW10 9NH, UK room-associated transmission risks. Furthermore, regulations in many centres only permitted essential personnel into the operating rooms, again limiting observational training opportunities. In addition to the cancellation of operating lists, there were early concerns about endoscopic surgery being an aerosol generating procedure that could potentially aid in the transmission of virus among theatre staff. The Royal College of Surgeons implemented guidelines to avoid endoscopic surgery in most cases, thus further impacting training in this area [1]. However, it emerged during the course of the pandemic that there was minimal risk of endoscopic procedures being singled out for enhanced viral transmission [2].

In the adult literature, many institutions have utilised a variety of methods to counteract the lack of operative training as reported by an Otorhinolaryngology program in the United States [3]. Simulation kits were given to the trainees on a weekly basis so that trainees could perform common otorhinolaryngology procedure simulation at home. In Singapore, hand surgeons benefitted from simulation models [4]. Trainees were given a weekly two to three hourly skill slots where they had dedicated time with a supervisor to practice and gain feedback. In Chile, mobile applications for remote laparoscopic teaching was implemented [5]. Trainees watched instructional videos on their phone, practiced the skill and uploaded a video of themselves performing the exercise before sending it to certified tutors from their online platform to receive personalised feedback within $72 \mathrm{~h}$. In 
the United Kingdom, the industry played an important supportive role for endoscopic training, with box trainers such as those offered by eoSurgical (eoSurgical Ltd, Edinburgh, UK) becoming increasingly common for trainees. eoSurgical has provided their online content for free for trainees during the pandemic with a prior purchase of the box [6]. Karl Storz UK (Karl Storz Endoscopy UK Ltd, Slough, UK) has also provided self-directed learning boxes with silicone models for face to face socially distanced endoscopic courses. Using these simulation tools allowed deliberate practice that could be continued at home or in the workplace allowing for social distancing.

In addition to simulation, many institutions have supplemented their skills learning by providing video-based education and online teaching sessions with access to highquality surgical teaching videos [7, 8]. Online tools, such as video libraries or multimedia resource atlases to show procedural images and anatomy have also been beneficial in bridging the gap in training. Studies have also suggested utilising mobile applications such as Touch Surgery (Touch Surgery Labs, London, United Kingdom) or iLappSurgery (iLappSurgery Foundation, The Netherlands) which provide interactive surgical detailed guides for trainees to perform procedures with detailed embryology, anatomy and step by step approaches. Social media has also proved to be an easily accessible way to share images and experiences for medical education $[7,9,10]$.

In the United Kingdom, the Royal College of Surgeons outlined how surgical trainees can maximise their training opportunities amidst the pandemic. This includes remote access for video observation in theatres, utilizing independent sector opportunities for training, simulation training, increasing number of trainees per case and for trainers to mention training risk at the team brief [11].

International paediatric endoscopic surgery conferences were done virtually and were offered at economical fees that allowed paediatric surgical trainees access to valuable lecture sessions. On the other hand, pre-Congress skill labs conducted during such events which involved expert faculty to offer valuable tips and tricks during hands-on sessions were missing. Many international paediatric endoscopic surgery hands-on courses conducted in state-of-the-art facilities which offered similar but more elaborate hands-on experience, were cancelled. From the trainee's perspective, although the ingenuity to keep ongoing education in paediatric endoscopic surgery was a welcome initiative, it lacked to bridge the gap in this hands-on skill-based training area of medicine.

There has been no collective or coordinated plan to specifically address the loss of paediatric endoscopic training. Although some institutions have maximised their resources in setting up hands-on training facilities during the pandemic, there has been a lack of unified approach which leads to large variations in opportunities available for trainees based at different centres nationally. The devastating impact of the initial pandemic in 2020, followed by a staggered recovery and a second wave in 2021 , has affected 1 year of hands-on training in paediatric endoscopic surgery. The importance of highlighting this fact is to raise awareness of a reduction in the achievement of specific skill levels for paediatric surgical trainees interested in a career in endoscopic surgery. Paediatric minimal access surgery is an exceptionally challenging field due to the extreme variations in the size of the patients; ranging from newborns to adolescents. Finding possible solutions to continue training in this field during the pandemic will require focused efforts from the educators and leaders of paediatric endoscopic societies and universities.

In order to have endoscopic paediatric surgeons of the future, training in this area must continue with innovate ways despite the setback endured due to the pandemic. Increasing the number of practical simulation sessions could be incorporated in the weekly educational program, which would be a step forward in this direction. As businesses around the world adapt and embrace working from home and technological advances, similar options must be created for paediatric endoscopic surgeons in training.

\section{References}

1. Royal College of Surgeons (2021) Intercollegiate General Surgery Guidance on COVID-19 UPDATE 2020. https://www. rcsed.ac.uk/news-public-affairs/news/2020/march/intercolle giate-general-surgery-guidance-on-covid-19-update. Accessed on 16 March 2021

2. de Leeuw R, Burger N, Ceccaroni M (2020) COVID-19 and laparoscopic surgery: scoping review of current literature and local expertise. JMIR Public Heal Surv 6:e18928. https://doi. org/10.2196/18928

3. Okland TS, Pepper JP, Valdez TA (2020) How do we teach surgical residents in the COVID-19 era? J SurgEduc 77:10051007. https://doi.org/10.1016/j.jsurg.2020.05.030

4. De Das S, Puhaindran ME, Sechachalam S, Wong KJH, Chong CW, Chin AYH (2020) Sustaining a national surgical training programme during the COVID-19 pandemic. Bone Jt Open 1:98-102. https://doi.org/10.1302/2633-1462.15.bjo-2020-0019

5. Jarry Trujillo C, Achurra Tirado P, EscalonaVivas G, CrovariEulufi F, Varas CJ (2020) Surgical training during COVID-19: a validated solution to keep on practicing. Br J Surg 107:e468e469. https://doi.org/10.1002/bjs.11923

6. eoSurgical (2021) eoSurgical 2021. https://www.eosurgical. $\mathrm{com} /$. Accessed on 16 March 2021

7. Doulias T, Gallo G, Rubio-Perez I, Breukink SO, Hahnloser D (2020) Doing more with less: surgical training in the COVID19 Era. J InvestigSurg. https://doi.org/10.1080/08941939.2020. 1824250

8. Imai TA, Soukiasian HJ, Truong A, Chau V, Amersi F (2021) The lasting footprint of COVID-19 on surgical education: a resident and attending perspective on the global pandemic. Am 
J Surg 14(4):337-339. https://doi.org/10.1016/j.amjsurg.2020. 12.046

9. Dedeilia A, Sotiropoulos MG, Hanrahan JG, Janga D, Dedeilias P, Sideris M (2020) Medical and surgical education challenges and innovations in the COVID-19 era: a systematic review. In Vivo (Brooklyn) 34:1603-11. https://doi.org/https://doi.org/ 10.21873/invivo. 11950

10. Zingaretti N, ContessiNegrini F, Tel A, Tresoldi MM, Bresadola V, Parodi PC (2020) The Impact of COVID-19 on plastic surgery residency training. Aesthetic PlastSurg 44:1381-1385. https://doi.org/10.1007/s00266-020-01789-w

11. JCST, ASiT, BOTA, CoPSS (2021) Making the most of every training opportunities - national bodies, trainers and trainee. $\mathrm{R}$ Coll Surg Engl 2020:1-5. https://www.rcseng.ac.uk/news-andevents/news/archive/maximising-training-opportunities-covid-19/. Accessed on 16 March 2021. 